\title{
A Metodologia ABCDE: Enfatizando a Criatividade no Design de Jogos Sérios
}

\section{Title: The ABCDE Methodology: Emphasizing Creativity in the Design of Serious Games}

\author{
Diego Sauter Possamai ${ }^{1}$, Marcelo da Silva Hounsell ${ }^{1}$, Isabela Gasparini ${ }^{1}$
}

'Programa de Pós-Graduação em Computação Aplicada (PPGCAP) - Departamento de Ciência da Computação (DCC) - Universidade do Estado de Santa Catarina (UDESC) Joinville, Santa Catarina - Brasil

dspossamai@gmail.com; \{marcelo.hounsell; isabela.gasparini\}@udesc.com

\begin{abstract}
Serious games (SG) have been criticized for their lack of creativity. The ABCDE methodology, that aligns creativity models with the use of brainstorming tools is presented to promote the convergent-divergent thinking and foster creativity. It can be added to the conceptual stage of game design focusing on the creation of game mechanics. The ABCDE methodology was built in four research cycles that involved analysis, proposition, application (selection, workshop) and evaluation. Evaluation using the Creative Product Analysis Matrix tool compared the creativity perceptions of game mechanics generated with and without using $A B C D E$. The results show benefits in terms of time spent and people involved while using the ABCDE methodology for a given game project that achieved the same high level of creativity when comparted to another methodology. We conclude that $A B C D E$ has potential to generate creative game mechanics and can be inserted as part of other game design methodologies, not just for $S G$.
\end{abstract}

Keywords. Creativity; Game Design; Serious Games; Brainstorm.

Resumo.Jogos Sérios (JS) têm sido criticados por sua falta de criatividade. A metodologia ABCDE, que alinha modelos de criatividade com o uso de ferramentas de brainstorming, é apresentada para promover o pensamento convergente-divergente e instigar a criatividade. Ela pode ser adicionada na fase conceitual do design de jogos com foco na criação de mecânicas do jogo. A metodologia ABCDE foi construída em quatro ciclos de pesquisa que envolveram análise, proposição, aplicação (seleção, workshop) e avaliação. A avaliação usando a ferramenta Creative Product Analysis Matrix comparou as percepções de criatividade de mecânicas de jogo geradas com e sem o uso da ABCDE. Os resultados mostram benefícios em termos de tempo gasto e pessoas envolvidas no uso da metodologia ABCDE para um determinado projeto de jogo que alcançou o mesmo alto nível de criatividade quando comparado com outra metodologia. Conclui-se que a ABCDE tem potencial para gerar mecânicas de jogo criativas e pode ser inserida como parte de outras metodologias de design de jogos, não apenas para JS.

Cite as: Possamai, D. S., Hounsell, M. S. \& Gasparini, I. (2021). The ABCDE Methodology: Emphasizing Creativity in the Design of Serious Games (A Metodologia ABCDE: Enfatizando a Criatividade no Design de Jogos Sérios). iSys: Revista Brasileira de Sistemas de Informação (Brazilian Journal of Information Systems), 14(1), 24-55. DOI: 10.5753/isys.2021.993 
Palavras-Chave. Criatividade; Design de Jogos; Jogos Sérios; Brainstorm.

\section{Introdução}

Jogos Digitais estão cada dia mais presentes em nossa sociedade. Seu impacto pode ser observado diariamente na mídia, na televisão, nos aparelhos dedicados a jogos que povoam as casas; nos aparelhos de celular que carregamos todo o tempo [BAKER 2014].

Embora pareça que a indústria de jogos esteja caminhando na direção certa, um desconforto cresce dentro dos estúdios de desenvolvimento e também por parte dos jogadores que consomem estes jogos digitais. Em seus primórdios, tudo era novo. Jogos eram diferentes, atrativos, criativos. Agora, a sensação que paira no ar é de estagnação, falta de novidades, pouca criatividade [HADZINSKY 2014] Uma forma de entender criatividade é como um conjunto de habilidades necessárias para produzir ideias que são originais e valiosas [STERNBERG 2001].

Shigeru Miamoto disse a Gamesindustry em 3 de julho de 2014: "Este ano a maioria do que foi exibido foram jogos de tiro violentos ambientados em locais realistas ou mundos fantásticos. Como muitos desenvolvedores competem nesta categoria, a maioria dos jogos era desse tipo. Isso é uma revelação da imaturidade criativa dos desenvolvedores de jogos nesta indústria”. O Governo da Coréia do Sul, por exemplo, através de seu programa Creative Korea fez anúncio oficial em 2016 dizendo: "que abrange também a indústria de jogos Coreana, que sofre com o lançamento contínuo de jogos de CRPG (Computer Role Playing Games) de ação com a mesma interface, mesmos modos de jogo, mesma história e estilo artístico muito similar".

Associada a esta indústria existem os Jogos Sérios (JS), que têm um objetivo além do entretenimento, como por exemplo a educação, reabilitação ou treinamento [ZYDA 2005]. Jogos sérios visam obter benefícios específicos em diversas áreas como educação [BUCHINGER, HOUNSELL e DIAS 2012], promoção da saúde [FARIAS et al. 2013], reabilitação [GRIMES, SANTOS e HOUNSELL 2018], dentre outros. Estes jogos são importantes devido ao seu objetivo ser os elementos sérios que o compõem em oposição ao puro e simples entretenimento dos jogos convencionais [MICHAEL e CHEN 2006].

Jogos sérios, assim como jogos convencionais, possuem um processo de desenvolvimento e necessitam de processos de design de jogo para tomarem forma [SCHELL 2008], mas não se tem conhecimento de uma metodologia de design de jogo, para jogos convencionais ou para jogos sérios, que enfatize o aspecto da criatividade. Da mesma forma que a criatividade afeta os jogos convencionais, ela também afeta os jogos sérios, mas nestes há um impacto maior devido às restrições existentes no desenvolvimento graças aos seus componentes sérios [MICHAEL e CHEN 2006; ALVAREZ e DJAOUTI]. A crise que afeta os jogos convencionais também afeta os jogos sérios.

Jogos Sérios são uma forma de abordar temas relacionados a educação, saúde e outras áreas que tem impacto direto na vida das pessoas e na sociedade. Portanto estão relacionados com os desafios da visão Sociotécnica da área de Sistemas de Informação [BOSCARIOLI, ARAUJO e MACIEL 2017]. Esta pesquisa busca, através da construção de uma metodologia, relacionar com a necessidade de novos modelos de processo para o desenvolvimento de Sistemas de Informação socialmente conscientes 
[PEREIRA, SOUZA e BARANAUSKAS 2015], para ser praticável com quaisquer grupos de pessoas e auxiliar na construção de jogos sérios que têm impacto na sociedade e na vida de pessoas que utilizam estes jogos.

Então, o objetivo deste trabalho é desenvolver uma metodologia de game design que facilite a criação de jogos criativos e que considere, principalmente, mas não exclusivamente, as restrições de jogos sérios.

\subsection{Escopo}

Este trabalho foca no projeto conceitual de mecânicas de jogo - que determinam descrição de regras e funcionamento dos elementos do jogo [BRATHWAITE e SCHREIBER 2009], por ser um dos primeiros passos no design de jogo, possui baixo risco, baixo custo e maior flexibilidade. Somado a isto, têm-se o foco nos projetos acadêmicos que não têm uma equipe de designers fixa nem contratada, e ainda, algumas vezes, há participação voluntária no desenvolvimento. Dentro do design de jogos, enfoque será dado à criação de mecânicas de jogos pois estas são consideradas as diferenças principais entre os jogos e pela competência dos pesquisadores ser maior na área computacional.

\subsection{Metodologia}

Foi realizado um mapeamento sistemático da literatura, para responder a pergunta específica - "Qual o estado da arte nas pesquisas sobre criatividade no processo de desenvolvimento de jogos?", visando identificar as relações de fomento da criatividade no desenvolvimento de jogos, ferramentas utilizadas, aplicações, avaliações e interpretações, seguido de um estudo aprofundado no tema de criatividade [POSSAMAI, HOUNSELL e GASPARINI 2018].

Em seguida foi realizada uma pesquisa exploratória, tipo de pesquisa que busca proporcionar maior familiaridade com o problema, de forma a torná-lo explícito ou para construir hipóteses [GIL 2007]. Isto resultou na proposição de uma metodologia que foi desenvolvida usando o ciclo do Design Science Research (DSR) na área de Sistemas de Informação [HEVNER et al. 2004], que sobrepõe um foco em três ciclos de pesquisa inerentes: o Ciclo de Relevância faz a ponte entre o ambiente contextual do projeto de pesquisa e as atividades do DSR; O Ciclo de Rigor conecta as atividades do DSR com a base de conhecimento de fundamentos científicos, experiência e expertise que informam o projeto de pesquisa; o Ciclo de Design central itera entre as atividades principais de construção e avaliação dos artefatos e processos de design da pesquisa. Seguiu-se um método [GLEASURE 2014] que gera meta-artefatos abstratos, onde a avaliação do design acontece de forma dinâmica. Este método ocorre com base na análise sistemática e síntese de artefatos existentes. Para Walls et al. (1992), meta-artefatos no desenvolvimento de sistemas de informação compreendem abordagens, métodos, técnicas e ferramentas.

A última parte desta pesquisa executou uma pesquisa experimental [GIL 2007] onde foi projetado um conjunto de mecânicas de JS sobre o tema "lateralidade" com a metodologia ABCDE com o objetivo de avaliar as mecânicas geradas de forma comparativa com mecânicas não geradas pela ABCDE para o mesmo tema utilizando-se a Matriz de Análise de Produto. 


\subsection{Estrutura do artigo}

A seção 2 apresenta o estudo sobre criatividade, sua conceitualização ao longo dos anos por diferentes estudiosos, modelos de criatividade, como estão estruturados e ferramentas para avaliação de criatividade associados a estes modelos, A seção 3 foca nas definições de jogos sérios, design de jogos, metodologias estabelecidas de design de jogos, a essência de mecânicas de jogos e ferramentas existentes na literatura que foram aplicadas para fomentar a criatividade no design de jogos. A seção 4 apresenta o mapeamento sistemático da literatura em busca dos trabalhos relacionados no uso de criatividade no processo de design de jogos. A seção 5 descreve a metodologia foco desta pesquisa, com o detalhamento da construção e implementação do workshop de fomento de criatividade no processo de design de jogos sérios com foco em mecânicas de jogos, suas iterações e modificações. A seção 6 apresenta o processo de avaliação da pesquisa e seus resultados. A seção 7 discute os resultados e limitações da pesquisa. A seção 8 recapitula os resultados obtidos na implementação da metodologia e apresenta uma lista com os trabalhos futuros.

\section{Criatividade}

Ocorre um consenso entre vários autores de que atos de criatividade não são eventos de natureza singular, mas um processo, relacionado a interação entre vários elementos cognitivos e afetivos. Segundo Finke et al (1996), o ato da criatividade possui duas etapas: uma de geração e outra exploratória.

- Na etapa de geração, uma série de modelos mentais tomam forma como possíveis soluções para um problema.

- Na etapa exploratória, estas várias soluções são avaliadas e uma delas é escolhida como a melhor solução.

Há evidências [HARING-SMITH 2006; KIM 2006; SAWYER 2006; KAUFMAN e STERNBERG 2007; SIMONTON 2004; DIAMOND et al. 2007; VANDERVERT et al. 2007] que sugerem que o processo criativo requer tanto o pensamento divergente quanto o convergente e que está associado a capacidades mentais que podem ser. o pensamento divergente, onde várias ideias surgem para um problema, mesmo que não relacionadas; o pensamento convergente, onde estas ideias começam a ser avaliadas e ocorre o foco de pensamento; pensamento analítico, quando a habilidade de compreender que uma ideia é original e nova em relação ao que já existe.

Pode-se observar a ferramenta de brainstorming criada por Osborn (1942), pois em sua concepção ele considera que a criatividade em grupo é superior a criatividade individual. Sua conclusão vem de resultados obtidos em atividades que demandavam resultados colaborativos. Brophy (2006) apresentou evidências de que grupos de indivíduos interagindo eram mais eficientes em solucionar problemas complexos de múltiplas partes do que por apenas um indivíduo. Entretanto, quando o problema consistia em apenas uma única parte, indivíduos geravam melhores resultados que um grupo e estas soluções possuíam características mais originais. Portanto, quando um indivíduo passa pela experiência de criatividade, este é o resultado de vários processos sob a influência de interação com grupos e o contexto social. 
A criatividade advinda da inspiração como aquela presente e associada a um Michelangelo ou Einstein é o que Kaufman e Beghetto (2008) chamam de criatividadeC (BIG C). A criatividade de mini-c é baseada no que Craft chama de "pensamento de possibilidade" [CRAFT 2000, pp. 3-4]. A criatividade mini-c não é um dom misterioso e inato de indivíduos raros. O pensamento criativo é um processo multicomponente, mediado por interações sociais, que pode ser explicado pela referência a habilidades cada vez mais compreensivas, como a flexibilidade cognitiva e o controle cognitivo amplamente distribuídos na população.

A criatividade advém do equilíbrio de três habilidades que podem ser desenvolvidas [STERNBERG 1985; STERNBERG e LUBART 1995; STERNBERG e WILLIAMS 1996]. A criatividade é vista pelos autores como uma habilidade chamada de capacidade sintética, que resulta na capacidade de gerar ideias novas e interessantes. Para eles, as pessoas chamadas de criativas são pensadores sintéticos particularmente bons, que fazem conexões entre coisas que outras pessoas não reconhecem espontaneamente. A capacidade analítica é considerada como a capacidade de raciocínio crítico. Pessoas com essa habilidade analisam e avaliam ideias. Capacidade prática é a habilidade de traduzir a teoria em prática e transformar ideias abstratas em realizações práticas.

Rhodes (1961) reuniu quarenta definições de criatividade e dezesseis definições de imaginação e propôs que essas definições se sobrepunham e se entrelaçavam. Categorizando as definições, ele criou um modelo de criatividade em 4 partes. Pessoa: refere-se à personalidade, intelecto, temperamento, físico, traços, hábitos, atitudes, autoconceito, sistemas de valores, mecanismos de defesa e comportamento; Processo: refere-se a motivação, percepção, aprendizagem, pensamento e comunicação; Ambiente: refere-se à relação entre os seres humanos e seu meio ambiente; Produto: resultado criado quando uma ideia se torna tangível e concreta; Dos quatro "P", o produto - uma ideia, processo ou objeto físico - é o que tem maior peso.

Os primeiros estudiosos da criatividade, como o de Guilford (1950), caracterizaram a criatividade como o resultado de um processo em duas fases: pensamento divergente e pensamento convergente [GUILFORD 1950]. Guilford definiu o pensamento divergente como a capacidade de produzir uma ampla gama de associações para um determinado estímulo ou de chegar a muitas soluções para um problema (para visões gerais do campo de diferentes perspectivas, ver [AMABILE 1996]; [SAWYER 2006]. Em termos neuro cognitivos, o pensamento divergente é referido como riqueza associativa [GABORA 2002; SIMONTON 2004], que é frequentemente medido experimentalmente comparando o número de palavras que um indivíduo gera de memória em resposta a palavras de estímulo em um teste de associação de palavras. Em contraste, o pensamento convergente refere-se à capacidade de se concentrar rapidamente na melhor solução para um problema.

A teoria [AMABILE et al. 2004] é um modelo abrangente dos componentes sociais e psicológicos necessários para um indivíduo produzir trabalho criativo. A teoria específica que a criatividade requer uma confluência de quatro componentes:

1) Uma pessoa intrinsecamente motivada;

2) Domínio de alta especialidade;

3) Alta habilidade no pensamento criativo;

iSys: Revista Brasileira de Sistemas de Informação (isys: Brazilian Journal of Information Systems) https://sol.sbc.org.br/journals/index.php/isys 
4) Trabalha em um ambiente de alta criatividade.

As pessoas são mais criativas quando se sentem motivadas principalmente pelo interesse, gozo, satisfação e desafio do próprio trabalho - e não por motivadores extrínsecos. Conhecimento está relacionado a toda informação relevante que um indivíduo tem sobre um problema; o pensamento divergente e o convergente podem ser usados em cima deste conhecimento, pois é a partir dele que se pode combinar elementos que não estão necessariamente associados e sua posterior análise.

O pensamento criativo está associado a divergência e convergência, onde soluções que fujam do convencional surgem como ideias, pela combinação de conhecimentos de áreas distintas e não relacionadas e pela capacidade de observar um problema de vários ângulos e maneiras diferentes, buscando romper as barreiras do status quo que o cercam através do pensamento analítico.

Amabile et al (2004) reforça o papel da motivação intrínseca como fundamental para a criatividade. Segundo ela, "temos encontrado várias evidências em favor da motivação intrínseca que chegamos no que chamamos de Princípio da Motivação Intrínseca na Criatividade: pessoas serão mais criativas quando estas sentirem que estamos motivadas primariamente por interesse, satisfação e desafio - e não por pressão externa”.

Duas abordagens estabelecidas na literatura são utilizadas para avaliar a criatividade em contextos diferentes, uma sobre abordagem de problemas [BASADUR e FINKBEINER 1983] e outra sobre percepção de criatividade em produtos [BESEMER 1998]. A metodologia ABCDE utiliza estas duas abordagens em etapas específicas.

\subsection{Escala Preferencial de Basadur}

A escala mede a mistura de preferências de um indivíduo para o processo criativo [BASADUR e FINKBEINER 1983]. O Basadur CPS Profile não é um teste de personalidade. Mede estados, não traços. É uma ferramenta para ajudar um indivíduo, equipe ou organização a entender como aumentar a criatividade e a inovação em um ambiente. Nenhum perfil ou estilo é considerado mais "criativo" do que qualquer outro.

Cada um dos quadrantes que compõe os estilos de criatividade possui uma descrição aprofundada:

- Quadrante 1 - Gerador: A atividade criativa nesse quadrante envolve obter conhecimento e compreensão por contato físico e envolvimento em atividades do mundo real e utilizar esse conhecimento para criar novos problemas, desafios, oportunidades e projetos potencialmente valiosos para definir e empreender por meio de solução e implementação subsequentes;

- Quadrante 2 - Conceitualizado: A atividade criativa nesse quadrante envolve obter conhecimento e compreensão mental ou trabalhar em abstração - analisando, ponderando e teorizando sobre as informações recebidas para criar uma conceituação ou modelo sólido do domínio do problema;

- Quadrante 3 - Otimizador: A atividade criativa neste quadrante envolve o ganho de conhecimento e compreensão mental, trabalhando em abstrato: analisando 
completamente um problema definido e utilizando esse conhecimento para desenvolver e avaliar ideias e opções e criar uma solução prática e ideal;

- Quadrante 4 - Implementador: Este quadrante envolve ganhar conhecimento e compreensão por contato físico e envolvimento no mundo real.

O gráfico de perfil é montado com base em um questionário. O questionário do CPSP consiste em 12 itens pontuados e seis itens distratores que não são pontuados.

\subsection{Matriz Criativa de Análise de Produto}

A Matriz Criativa de Análise de Produto (CPAM) [BESEMER 1998] pode ser usada como um framework sobre a criatividade manifestada em muitos tipos diferentes de produtos. O modelo pode ser usado em relação a obras de arte, ideias de novos produtos na fabricação ou ao considerar artefatos do processo criativo. O modelo está fundamentado em três fatores relacionados: Novidade, Resolução, Elaboração e Síntese. Dentro das três dimensões, nove facetas dos componentes são feitas em hipóteses. Em Novidade estão as facetas originalidade e surpresa. Na dimensão de Resolução, as facetas são valiosas, lógica, útil e compreensível. A terceira dimensão do modelo, Elaboração e Síntese, inclui as seguintes facetas: orgânica, elegante e bem trabalhada.

O primeiro dos três fatores é a novidade. Isso inclui a consideração de novos materiais, novos processos, novos conceitos e outros elementos de novidade no produto ou ideia de produto. Elementos de novidade podem ser refletidos em julgamentos de originalidade e às vezes são marcados por expressões de surpresa, deleite ou - às vezes choque do usuário potencial.

O segundo fator importante na criatividade é a resolução. Este termo se refere a quão bem o produto faz o que deveria fazer, se é lógico, funciona e as pessoas conseguem entender sua utilizada e como usar.

O terceiro indicador é denominado elaboração e síntese. Essa dimensão está relacionada à maneira como o conceito do produto é elaborado por meio do novo produto. Elaboração e síntese referem-se ao fato de que às vezes o design inicial é elaborado e tornado mais complexo por meio da solução. Essa dimensão às vezes é chamada de estilo, mas não deve ser confundida com estilo no sentido de um produto "estiloso". A dimensão de elaboração e síntese considera o quão bem as partes do produto estão integradas em uma declaração coerente, quão bem elaborado o produto parece e quão elegante ele parece para o consumidor.

A matriz usa 55 pares de adjetivos, a partir dos quais os avaliadores selecionam pontos ao longo de um continuum de 1 a 7 para representar sua avaliação do conceito do produto. Elementos de novidade que fortalecem o design ao torná-lo mais criativo podem ser vistos como agregando valor à ideia do produto.

Com base nessa teoria, foi desenvolvida a Escala Semântica de Produto Criativo (CPSS) [BESEMER 1998; BESEMER e O'QUIN 1986, 1987, 1993; O'Q.M \& BESEMER 1989]. O desenvolvimento desta escala para medir a criatividade em produtos teve início em 1980, quando o modelo teórico foi criado, a partir de uma revisão da literatura em que eram citados critérios de criatividade em produtos [BESEMER e TREFFINGER 1981]. A geração de itens tomou a forma de listas de critérios citados nos diversos artigos revisados. De 1981 a 1986, várias versões de 
instrumentos de autorrelato (variando de 70 a 110 itens) foram desenvolvidas para testar o modelo CPAM. Esses instrumentos foram testados usando diferentes tipos de produtos e vários grupos de juízes leigos.

O CPSS [BESEMER 1998] é um instrumento de avaliação concebido para avaliar a criatividade que se percebe manifestada nos produtos. O CPSS postula que juízes não treinados, usando um instrumento validado e confiável, podem fazer julgamentos informados sobre criatividade em produtos. A capacidade de usar juízes não treinados em estudos de criatividade aumenta a generalização dos resultados para 0 ambiente natural e desmistifica a noção de criatividade nos produtos. Ele também permite que os usuários melhorem a criatividade dos produtos em consideração, fortalecendo os atributos mais fracos.

O CPSS é um instrumento de avaliação baseado no CPAM, composto por uma série de pares de adjetivos bipolares em escalas de 7 pontos. O instrumento contém facetas que medem respostas de avaliadores as suas percepções dos produtos em avaliação. Cada faceta contém quatro ou cinco pares de itens relacionados à faceta. As pontuações de uma faceta são construídas a partir da média das pontuações dos pares de itens. O CPSS pode ser utilizado em vários domínios e por juízes não especialistas.

Sternberg e Williams (1998) e Koestler (1964) tocaram na promoção da criatividade com técnicas de ideação e geração/combinação de ideias, elementos presentes no brainstorming sendo este último portanto, um recurso útil para a criatividade. As colocações de Mestre (2005) sobre a necessidade de que pessoas envolvidas em processos de geração de ideias e soluções criativas possam interpretar as informações que recebem para gerar novas ideias e da necessidade da flexibilidade cognitiva de Ausubel (2000) relacionado a ter um ambiente que permita pensar e evoluir ideias, tem relação com o que Amabile (2004) apresenta em sua esfera de pensamento criativo na Teoria da Criatividade Componencial. Esta mesma teoria é uma evolução do Modelo 4P. Ambas as teorias, Modelo 4P e Teoria da Criatividade Componencial lidam com produtos criativos, onde o foco está no que foi gerado e seu resultado criativo ao invés de focar em pessoas criativas.

\subsection{Embasamento da metodologia ABCDE}

Não há um consenso sobre quantos critérios são necessários para obter uma avaliação confiável de produtos criativos. Uma das visões defende que o produto criativo deve ser novo e útil [STERNBERG e LUBART, 1999]. Esses dois critérios são considerados o "padrão - ouro" para avaliação de produtos criativos [RUNCO e JAEGER, 2012]. Tanto "novo" quanto "útil" são conceitos relativos e sofrem influência de contextos pessoais, sociais, culturais e históricos em que o produto foi gerado. Pesquisadores [SIMONTON, 2012] vêm tentando discernir os indicadores objetivos e subjetivos da criatividade relacionados a estes dois conceitos. A Matriz Criativa de Análise de Produto [BESEMER 1998] procura sintetizar uma avaliação de produto criativo que está relacionado a "novo" e "útil" em uma escala que permita discernir se um produto é criativo ou não.

Percebe-se então que há espaço para uma exploração na forma em que a criatividade pode ser promovida e abordada no âmbito de "processos", e não somente no âmbito do indivíduo. Ou seja, é viável buscar gerar resultados criativos promovidos 
por um "processo", em contraponto a promoção de criatividade apenas nas habilidades individuais.

A Metodologia ABCDE têm como uma de suas premissas o foco no fomento da criatividade no processo. Esta abordagem permite envolver quaisquer indivíduos na concepção de um artefato, mas o processo deve ser meticulosamente instrumentado. Esta compreensão estabelece o fundamento do porquê uma metodologia é utilizada como uma solução possível para abordar o problema da criatividade nos jogos sérios.

\section{Game Design e Jogos Sérios}

Pode-se entender Jogos Sérios como aplicações que mesclam aspectos sérios como o ensino, a aprendizagem, a comunicação e a informação, com o lúdico e interativo fornecido pelos videogames, sendo o primeiro o principal objetivo e não somente o entretenimento [MICHAEL e CHEN 2006; ALVAREZ e DJAOUTI 2011 ].

Zyda (2005) define que Jogos Sérios são jogos em que um propósito sério, como a educação, treinamento ou reabilitação, é o objetivo principal. Neste contexto há uma diferenciação entre Jogos Sérios, que possuem propósitos previamente definidos e estruturados, dos jogos para entretenimento.

Existem muitas definições sobre game design e uma das mais simples é a de Schell (2008) em que ele diz ser o ato de decidir o que um jogo deveria ser. Brathwaite e Schereiber (2009), que atua como game designer, diz que "game design é o processo de criar os desafios e as regras de um jogo", e continua dizendo que para um bom game design é preciso criar objetivos os quais o jogador sinta-se motivado a alcançar e regras que o jogador precisa seguir ao fazer escolhas significativas em prol desses objetivos. $\mathrm{O}$ trabalho de game design está relacionado, portanto, a criação, desenvolvimento e produção de um jogo.

Jogos Sérios (JS) são idealizados e desenvolvidos utilizando métodos de Design como o MDA [HUNICKE, LEBLANC e ZUBEK, 2004), DDE [WALK, GÖRLICH e BARRETT 2017], Elemental Tetrad [SCHELL 2008], ou o MTDA [RALPH e MONU 2014]. Cada uma destas metodologias apresenta etapas distintas, mas um dos elementos presentes em todos estes métodos são as mecânicas de jogo. A mecânica do jogo deve ser a primeira coisa a ser considerada no projeto porque é a fonte primária de entretenimento em todos os jogos digitais [ADAMS 2010], e pelo fato de que JS possuem restrições que afetam diretamente as mecânicas de jogo e tornam seu processo de design menos trivial.

Devido a isto o foco desta pesquisa está no fomento da criatividade nas mecânicas de jogos. Tanto o MDA - Mechanics, Dynamics and Aesthetics [HUNICKE, LEBLANC, ZUBEK 2004] quanto o DDE - Design, Dynamics and Experience [WALK, BARRET, GORLICH 2017], o Elemental Tetrad [SCHELL 2008] e o MTDA + N - Mechanics, Technology, Dynamics, Aesthetics \& Narratives [RALPH e MONU 2014] trazem de forma clara e distinta as mecânicas de jogo inseridas no processo de design, logo nos estágios iniciais. Os processos e frameworks conhecidos de game design são distintos, mas todos dão importância à fase inicial da concepção das mecânicas de jogo.

Jogos sérios possuem restrições no seu design para atender os requisitos de seu espectro de aplicação sério. Estas restrições afetam as mecânicas do jogo e sua 
construção [ERB et al. 2012]. Isto reforça a necessidade do foco no fomento da criatividade no processo de design de jogos com foco em mecânicas de jogos, para contrapor estas restrições.

\section{Trabalhos Relacionados}

Foi realizado um Mapeamento Sistemático da Literatura [POSSAMAI, HOUNSELL e GASPARINI 2018] para buscar entender como a criatividade está sendo estimulada no design de jogos digitais. Ocorreram algumas dificuldades durante a pesquisa relacionadas a própria definição de criatividade, pois os autores que tratam deste tema possuem abordagens diferentes no entendimento e definição de criatividade, bem como a falta de clareza de como estas teorias estão alinhadas ou sendo utilizadas nos artigos explorados teve impacto na compreensão dos dados obtidos.

Existem propostas para uso/fomento de criatividade no processo de design de jogos; estas propostas encontram-se ligadas a estudos de caso específicos, muitas não deixam claro em qual ou quais teorias de criatividade estão baseadas; há um foco em artefatos de construção própria, seguida por técnicas associadas a Brainstorming e geração de ideias; ocorre uma dificuldade de se mensurar e validar as propostas existentes pois as próprias definições de criatividade variam muito de autor para autor. Há, portanto, espaço para que novas propostas surjam e sejam direcionadas ao processo de design de jogos digitais de forma mais ampla, independentemente do tipo de jogo, temática ou público-alvo.

Esta pesquisa foi realizada em 3 mecanismos de busca de ampla cobertura de artigos e identificou que, apesar do número de artigos sobre criatividade no design de jogos vir crescendo nos últimos dez anos, estes artigos têm sido em pequena quantidade (apenas 61 distintos) e pouco explícitos quanto a sua base teórica e quanto a sua proposta como um todo e até quanto a forma de avaliação da própria contribuição.

Entretanto pode-se observar: (i) uma predominância quanto a quantidade de artigos no mecanismo Science Direct, (ii) propostas no formato de framework, (iii) avaliação na forma de estudo de caso e coletas de dados em grupo, (iv) não envolvimento de recursos computacionais para aplicação da proposta, (v) a maioria voltada para jogos de entretenimento e (vi) usando artefatos específicos para cada caso.

Os dados coletados sugerem que a pesquisa sobre a criatividade no game design é um tema novo sem uma tendência identificada quanto a fundamento, técnica e procedimentos. Sendo assim, a área requer amadurecimento e, ao mesmo tempo, fomento. Métodos estão sendo estabelecidos de forma a sistematizar a criatividade como parte integrante deste processo. Alguns destes encontrados na literatura são apresentados a seguir. Utilizando o critério de inclusão com (a) foco no aspecto criatividade no game design e (b) apresentar ferramenta, metodologia e métodos relacionados a criatividade, foram localizados alguns trabalhos, detalhados a seguir.

\subsection{Sala 5555 (Room 5555)}

Três aspectos são enfatizados para um processo criativo de design de jogos [FULLERTON 2008]: realização de sessões de brainstorming em ambientes que sejam playful, testar as ideias de design de jogos geradas, e a criação de protótipos físicos que permitam o teste destes jogos em estágios iniciais do design. 
Além disto, o processo de design e playtest de jogos requer espaços onde os participantes possam jogar e conversar sobre os jogos e as estruturas que os compõe. A importância de protótipos em estágios iniciais do design devem lembrar os participantes que devem focar na criatividade e no playtest ao invés de tentar criar soluções de programação [GOTTEL e SCHILD 2011]. O método Room 5555 enfatiza a criação de espaços apropriados para lidar com estes três aspectos e promover nos designers de jogos a busca pela inovação, descoberta de novas possibilidades e novas formas de solucionar os problemas de design de jogos de forma criativa.

\subsection{Cartas de Esforço (Exertion Cards)}

Hornecker (2010) traduz temas abstratos em perguntas com as quais os designers possam trabalhar. As Cartas de Esforço foram considerados úteis pelos participantes nos workshops para a tarefa criativa de projetar um jogo de esforço. Os participantes expressaram que as cartas os apoiavam em sua tarefa, reforçando a utilidade das cartas de projeto e, por sua vez, a utilidade do modelo.

As cartas conseguiram ajudar os participantes a decompor a tarefa em elementos individuais. Isso resultou em participantes percebendo que eles poderiam ter negligenciado um aspecto importante se eles não tivessem usado uma carta específica. Os autores concluem que o uso das cartas em um workshop, auxilia no processo de geração de ideias (brainstorming), que sustentado pelo trabalho em equipe gera resultados criativos.

\subsection{Rabiscando Jogos (Game Sketching)}

Game Sketching [AGUSTIN, CHUANG e DELGADO 2007] não é um software ou uma solução para um único problema pontual. O uso do Game Sketching permite a experimentação com baixo risco. O formato de sketching é uma mistura de texto e imagens e sua função é apresentar os conceitos de design do jogo antes do desenvolvimento de protótipos, permitindo desta forma um custo menor e uma maior facilidade de alteração dos elementos do jogo.

O Game Sketching é uma exploração do espaço de ideias dentro da indústria de jogos, que é mais consistente nos estágios iniciais de design (game design), onde a presença de tecnologia é menor.

\subsection{Jogo de geração de ideias (Ideia Generation Game)}

O Idea Generation Game tem por objetivo de promover a geração de ideias inovadoras e surpreendentes [DANSEY e STEVENS 2008].

De acordo com Dansey e Stevens (2008) o jogo é conduzido da seguinte forma: todos os jogadores ficam juntos em um ambiente descontraído pela duração de 2 horas. Ocorrem três interações do processo de brainstomring durante o jogo, cada uma consistindo de 10 minutos de geração de ideias, 10 minutos de avaliação e discussão e 5 minutos de descanso. Durante a fase de geração, os jogadores devem pensar na maior quantidade de ideias possíveis escrevendo as ideias em papel seguindo a estrutura de componentes na ideia (entre 3 a 5 dos elementos): social/comportamental/espacial e temporal. 
A partir dos resultados do jogo e das discussões, os autores verificaram que a falta de motivação dos participantes é um risco muito real que afeta a condução das sessões de geração de ideias.

\subsection{Padrões e Storyboard}

Para propósitos de design de jogo, storyboards precisam conter representação de ideias que sejam efetivas e eficazes. A representação formal de tais ideias é chamada de pattern [WINTER e JANTKE 2014].

A criação de padrões adaptativos permite que essas permutações gerem novas possibilidades e promovem o processo criativo durante o design do jogo e podem ser implementados de forma a mudarem durante o funcionamento do jogo, adaptando-se ao que o jogador faz no próprio jogo.

Utilizando-se os grafos e os storyboards como relações entre cenas, traduzindoos em padrões (patterns) é possível, segundo os autores, definir estruturas de grafos como padrões para determinados tipos de jogos ou para gameplay específicos dentro de um jogo, como diálogos ou mapas diferentes dependendo do caminho que o jogador escolher trilhar com o personagem.

Seguindo o raciocínio de Adams (2010) de que a mecânica do jogo deve ser a primeira coisa a ser considerada no projeto porque é a fonte primária de entretenimento em todos os jogos digitais, e observando-se os principais modelos de Design de Jogos, é possível observar a importância das mecânicas de jogos na estrutura do design um jogo, seja ele para o jogo convencional ou para jogos sérios. As mecânicas definem como um jogo funciona e como o jogador interage com o jogo. Sem elas, não há jogo (ADAMS, 2010). As abordagens apresentadas acima atuam de forma pontual em situações como prototipagem, geração de ideias, permuta de elementos de história (storyboard) ou temáticas bem definidas como as Cartas de esforço, e não necessariamente em mecânicas de jogos aplicáveis a qualquer tipo de jogo e que considere as restrições dos jogos sérios durante o processo em que são executadas. Portanto, apresenta-se no próximo capítulo uma proposta de metodologia para o fomento da criatividade em mecânicas de jogos sérios.

A Tabela 1 apresenta um comparativo entre as abordagens analisadas neste capítulo e a metodologia $\mathrm{ABCDE}$ proposta por esta pesquisa. O diferencial está na objetividade em ter bases claras na teoria de criatividade que a metodologia usa, instrumentos claros de agrupamento de pessoas que participam do processo da metodologia, avaliação objetiva utilizando ferramentas existentes na literatura científica e o uso das ferramentas utilizadas por abordagens diferentes, estruturadas no processo da ABCDE. 
Tabela 1. Comparativo entre abordagens e principais elementos

\begin{tabular}{|c|c|c|c|c|c|c|}
\hline Abordagens & $\begin{array}{c}\text { Necessidade } \\
\text { de } \\
\text { computador } \\
\text { ou software } \\
\text { especifico? }\end{array}$ & $\begin{array}{c}\text { Ferramenta } \\
\text { Principal }\end{array}$ & $\begin{array}{c}\text { Foco da } \\
\text { promoção } \\
\text { de } \\
\text { criatividade }\end{array}$ & $\begin{array}{c}\text { Avaliação } \\
\text { dos } \\
\text { resultados? }\end{array}$ & $\begin{array}{l}\text { Estratégia } \\
\text { para } \\
\text { agrupar } \\
\text { pessoas? }\end{array}$ & $\begin{array}{l}\text { Define qual } \\
\text { teoria de } \\
\text { criatividade } \\
\text { usa como } \\
\text { base? }\end{array}$ \\
\hline Sala 5555 & Não & Brainstorming & Indivíduo & Subjetiva & Não & Não \\
\hline $\begin{array}{l}\text { Cartas de } \\
\text { Esforço }\end{array}$ & Não & $\begin{array}{l}\text { Combinação } \\
\text { de elementos }\end{array}$ & Indivíduo & Subjetiva & Não & Não \\
\hline $\begin{array}{c}\text { Game } \\
\text { Sketching }\end{array}$ & Não & Brainstorming & Indivíduo & Subjetiva & Não & Não \\
\hline $\begin{array}{l}\text { Jogo de } \\
\text { geração de } \\
\text { ideias } \\
\end{array}$ & Não & Brainstorming & Indivíduo & Subjetiva & Não & Não \\
\hline $\begin{array}{c}\text { Padrões e } \\
\text { Storyboard }\end{array}$ & Não & $\begin{array}{l}\text { Combinação } \\
\text { de elementos }\end{array}$ & Indivíduo & Subjetiva & Não & Não \\
\hline $\begin{array}{c}\text { Metodologia } \\
\text { ABCDE }\end{array}$ & Não & $\begin{array}{c}\text { Brainstorming } \\
\text { Combinação } \\
\text { de Elementos }\end{array}$ & Processo & Objetiva & Sim & Sim \\
\hline
\end{tabular}

Fonte: próprio autor.

\section{Metodologia ABCDE}

A metodologia ABCDE (Amabile, Brainstorm, Convergente-Divergente, Evolutivo) foi construída utilizando-se a DSR e a estrutura apresentada por Hevner et al. (2004): no quesito ambiente, a metodologia foi estruturada para ser: aplicada com qualquer grupo de pessoas, não havendo a necessidade de especialistas; possível de ser integrada em qualquer estrutura organizacional $\mathrm{e}$; independente de tecnologias específicas. Os problemas a serem abordados são os relacionados ao desenvolvimento de jogos sérios criativos, suas restrições e demandas de pessoal especializado e tempo de desenvolvimento. As características são a base do ciclo de relevância onde os requisitos são testados em campo.

O quesito base de conhecimento, que dá forma ao ciclo de rigor, advém das teorias de criatividade, ferramentas para medição de criatividade, design de jogos sérios, métodos, ferramentas e frameworks já existentes na literatura e resultam em um metaartefato, construído de acordo com o método de Gleasure (2014), onde foram realizados:

a. Identificar o conjunto de resultados comportamentais desejados para o design: o comportamento desejado é uma alta percepção de criatividade nas mecânicas geradas pela $\mathrm{ABCDE}$ por profissionais de áreas associadas a desenvolvimento e uso de jogos sérios; 
b. Identificar uma variedade de artefatos existentes que, quando considerados em grupo, apresentam o conjunto desejado de resultados comportamentais: o MSL trouxe ferramentas, métodos e frameworks utilizados no contexto de fomento de criatividade em jogos sérios. Estes artefatos tiveram seus elementos extraídos e combinados de forma a atingir o comportamento desejado;

c. Identificar as características tecnológicas, infra estruturais e processuais diferenciadoras dos artefatos existentes selecionados: o MSL trouxe as características predominantes em pesquisas, em especial a não necessidade de uso de tecnologia computacional ou a construção de artefatos específicos e a predominância no uso do brainstorm;

d. Analisar as relações entre os recursos-chave de design e os resultados comportamentais associados e formalizar isso na forma de um meta-artefato: do estudo das teorias de criatividade, ferramentas de medição de criatividade, design de jogos e dos resultados do MSL o meta-artefato gerado foi a Metodologia ABCDE.

O ciclo de design da metodologia ABCDE para obter elevada percepção de criatividade de mecânicas de jogos sérios seguiu um processo iterativo composto das seguintes etapas, que foram inspiradas pelas fases do DSR:

1. Proposição dos procedimentos;

2. Execução com participantes;

3. Avaliação com especialistas e/ou própria;

4. Definição de soluções de melhorias;

Este processo foi executado quatro vezes, até que as etapas 3 e 4 não gerassem modificações significativas. Os resultados da última execução (propostas de mecânicas) foram então comparados com uma outra proposta existente, para o mesmo tema de jogo sério com as mesmas restrições, mas obtida sem a utilização da metodologia ABCDE a seguir, os ciclos são detalhados.

\subsection{Visão Geral}

A Figura 1 apresenta uma representação visual da metodologia ABCDE, onde no lado esquerdo estão as cinco etapas principais da metodologia, sendo A para referenciar a Criatividade Componencial de Amabile; B para referenciar a ferramenta de Brainstorming; C e D para referenciar as estratégias Convergente-Divergente e E para referenciar o ciclo Evolutivo do uso do brainstorming com as ideias geradas. As pessoas selecionadas utilizam as ferramentas de brainstorming, onde os modelos de criatividade Neo-Darwinian (N-D) e Neo-Lamarckian (N-L) guiam o processo de geração de ideias de mecânicas de jogos de forma a que estas estejam direcionadas aos objetivos sérios de um jogo e também respeitem suas restrições sérias.

A interação entre as pessoas que formam os grupos de trabalho, e a iteração sobre as ideias com as ferramentas de brainstorming em um ciclo estruturado utilizando elementos verbais (palavras) e desenhos (sketches) faz o ciclo evolutivo avançar. Todas estas tapas estão concentradas em mecânicas para jogos sérios, com uma priorização das ideias geradas em relação aos objetivos e restrições (das que mais atendem as que menos atendem). 

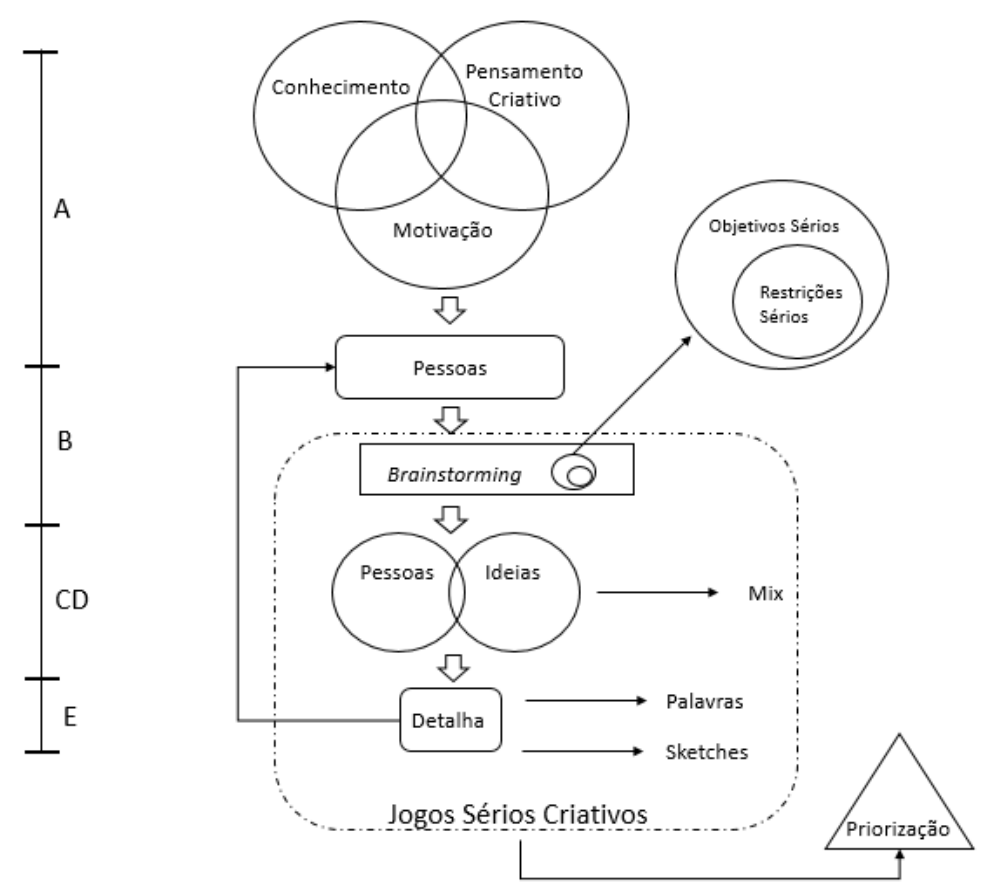

Figura 1. Metodologia ABCDE

O pilar incorporado para sustentar a metodologia é a Teoria Componencial de Criatividade (TCC) [AMABILE 1983]. Nela, existem três esferas principais que, quando interagem, resultam na criatividade: Conhecimento, Motivação e Pensamento Criativo. No contexto desta pesquisa, estas esferas foram abordadas da seguinte forma:

- Conhecimento: em tratando-se de jogos, conhecimentos distintos a gêneros de jogos e seu desenvolvimento, contribuem para a formação de grupos heterogêneos de pessoas, que são importantes para a geração de diferentes ideias [Amabile 1996];

- Motivação: Amabile (2004) considera o papel da motivação intrínseca como fundamental para a criatividade e que as pessoas serão mais criativas quando estas sentirem que estão motivadas primariamente por interesse, satisfação e desafio - e não por pressão externa;

- $\quad$ Pensamento Criativo: Amabile (2004) define como sendo a capacidade que as pessoas têm de se aproximar de um problema de forma imaginativa e de serem flexíveis na abordagem. A Escala Preferencial de Basadur [BASADUR, FINKBEINER 1983] pode ser utilizada para mapear quais as características que a pessoa apresenta associadas a 4 perfis distintos de criatividade (Implementador, Gerador, Otimizador, Conceitualizador).

As premissas principais adotadas no workshop são:

1. foco na promoção da criatividade nas mecânicas de jogo [ADAMS 2010];

2. uso da ferramenta de brainstorming, associada aos modelos de criatividade Neo-Darwinian e Neo-Lamarckian [JOHNSON-LAIRD 1988];

3. os modelos de criatividade estão associados ao pensamento Divergente e Convergente [GUILFORD 1950]; 
4. uso de ferramentas de Game Sketching [AGUSTIN, CHUANG, DELGADO, 2007];

5. baseada no Método 635 [ROHRBACH 1968] para definir o número de participantes - total e 6 , e a quantidade de ideias geradas - 3 por rodada;

6. separação em pequenos grupos com duas pessoas [THORNBURG 1991] que tem potencial de gerar mais ideias criativas;

7. uso de técnicas de combinação e rotação de ideias [GESCHKA, et al. 1981], onde as ideias rodam entre grupo no brainstorming entre etapas do workshop, mas os grupos formados se mantêm.

8. adoção do conceito de criatividade da Teoria da Criatividade Componencial [AMABILE 1983];

9. uso da Escala Preferencial de Basadur [BASADUR, FINKBEINER 1983] para selecionar participantes;

10. convite motivacional no formulário de seleção de voluntários.

\subsection{Seleção de Participantes}

Um formulário foi desenvolvido com objetivo de selecionar participantes para $\mathrm{o}$ workshop. Visto que estes participantes podem ser quaisquer pessoas, objetiva-se um grupo heterogêneo, devido ao fato de o brainstorming funcionar melhor com este tipo de formação de equipe [AMABILE 1996]. Os aspectos considerados dos participantes foram: conhecimentos sobre tipos de jogos, analisado na forma de gêneros de jogos que o participante conhece e/ou tem contato; percepção de quais áreas de atuação dentro de jogos que o participante considera que está inserido ou gostaria de atuar e; a Escala Preferencial de Basadur (ver anexo 3 em [POSSAMAI 2020]).

Os participantes são selecionados com base nestas características em um cálculo de Distância Manhattan $\left(\sum_{i=1}^{n}|p i-q i|\right.$, onde para 2 pontos seria $\mathrm{d}=|\mathrm{x} 2-\mathrm{x} 1|+\mid \mathrm{y} 2-$ y1I), que consiste na distância entre dois pontos medidos ao longo dos eixos em ângulos retos [BLACK 2006]. Quanto maior a distância entre dois candidatos, mais diferentes eles foram considerados. O método 635, de Bernd Rohrbach publicado em 1968 utiliza grupos de 6 pessoas gerando 3 ideias a cada 5 minutos; Thornburg (1991) cunhou o termo Creative Production Percent (CPP), que define o percentual de performance de um grupo em relação a um indivíduo no brainstorm. Quanto maior o número de participantes, menor é este valor. Ele aumenta até que se chegue a grupos de 2 pessoas, chamado de Dyad. Esta tem um CPP maior que o de um indivíduo. Partindo do Método 635, são selecionadas 6 pessoas (premissa 5).

\subsection{Workshop}

Uma vez selecionadas e pareadas as pessoas, executa-se o workshop, que consiste em um encontro estruturado, com fases definidas de geração de ideias, incrementadas com fases de permutação e combinação de ideias. Esta é a estrutura fundamental da metodologia $\mathrm{ABCDE}$ e os conceitos de mecânicas de jogos são gerados para um determinado tema de jogo sério e suas respectivas restrições.

São utilizadas as seguintes ferramentas: (i) brainstorm New-darwinian (N-D) e New-Lamarckian (N-L); (ii) Game Sketching, o Jogo de Geração de idéias utilizando os 
modelos Neo-Darwinian e o modelo Neo-Lamarckian, respectivamente nenhuma restrição e restrições prévias. O modelo Neo-Lamarckian pode ser associado diretamente as restrições de design existentes em JS. Ambos os modelos, N-D e N-L, podem ser relacionados, respectivamente, ao processo de pensamento divergente e convergente, já que o divergente consiste na maior quantidade possível e em todas as direções possíveis para ideias, e o convergente em agrupar todas estas ideias, combinálas e estruturá-las de forma que sejam utilizáveis [DANSEY e STEVENS 2008]. Estes modelos influenciaram a estrutura como o workshop foi formatado.

Furnham e Yazdanpanahi (1994) afirmam que sessões de brainstorming podem resultar em medo de avaliação, desinteresse de atuar em grupo (não sente satisfação individual) e bloqueio de produção, os quais podem prejudicar o processo de geração de idéias. O uso destes dois modelos de criatividade (N-D e N-L) associados ao brainstorming auxilia no processo de minimização destes problemas levantados, de acordo com Dansey e Stevens (2008). Parnes (1961) e Sowrey (1989) indicam uma forte relação entre o número de técnicas de ideação e o número de produtos de sucesso.

Portanto, o workshop será um ciclo brainstorming Neo-Lamarckian e NeoDarwinian (devido ao pensamento convergente-divergente) com detalhamento escrito e visual, envolvendo ciclos de geração e permutação de ideias. A estrutura é apresentada na Figura 2. Na esquerda estão as entradas em cada uma das fases e na direita as saídas. Ao centro estão listadas cada uma das etapas e o elemento principal que compõe cada uma delas.

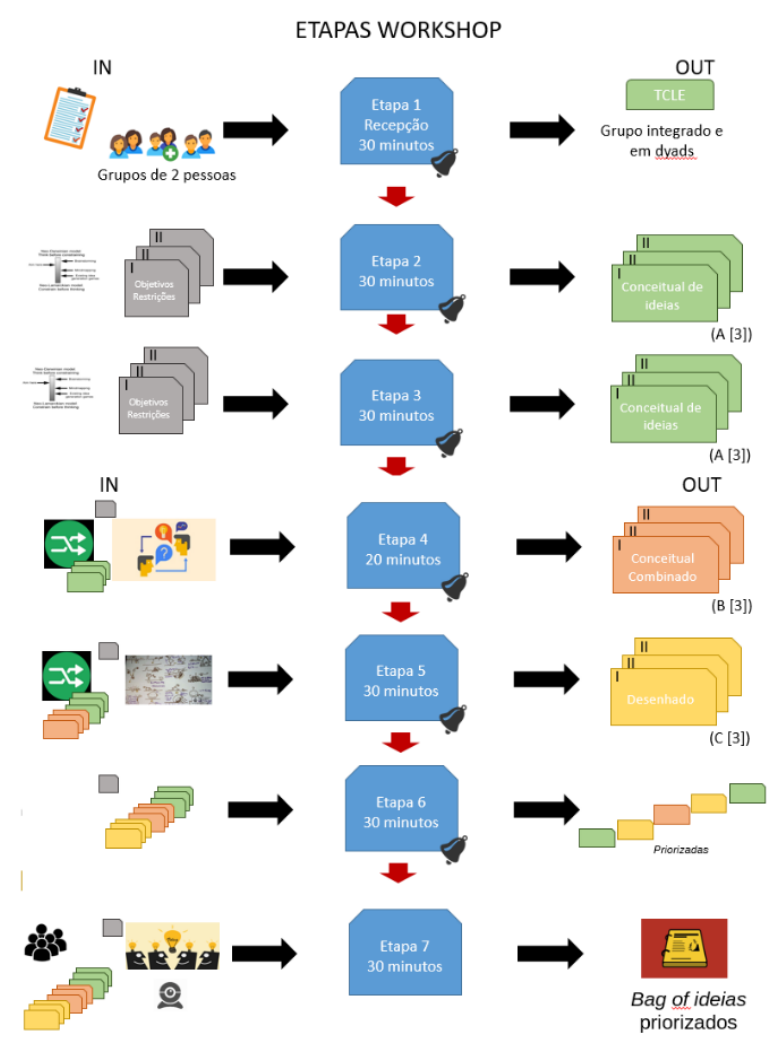

Figura 2. Etapas do Workshop versão final 
As etapas do workshop da Figura 2 são detalhados a seguir.

Etapa 1: Recepção

Apresentar restrições do jogo - o que são restrições em JS e como eles afetam o desenvolvimento do jogo e a concepção de mecânicas de jogo. Neste momento não são apresentadas as restrições do jogo que será tratado no workshop. O objetivo é que os participantes compreendam o que são restrições e o impacto delas no design de JS. Esta etapa dura 30 minutos. Uso de sino para indicar a passagem desta etapa para a próxima.

Etapa 2 - Ideias N-D

Esta etapa é baseada na geração de ideias por brainstorm, utilizando o modelo Neo-Darwinian (N-D). Divide-se os participantes em duplas (Dyads). Cada dupla recebe um conjunto de folhas denominadas "Guia de Trabalho" (contida no Apêndice 7 [POSSAMAI 2020]) com a numeração I e II. Nesta primeira etapa o guia instrui os participantes sobre os objetivos do jogo (I) e a escrever 1 ideia por folha, qual folha utilizar (folhas verdes) e como descrever a ideia de forma textual, utilizando descrições objetivas e com palavras chaves (II).

Com base no conceito de jogo, sem considerar as restrições (Neo-Drawinian), cada integrante do grupo busca escrever, de forma conceitual e com os detalhes que julgar necessário, em uma folha de papel, mecânicas de jogo adequadas ao conceito. Não há restrições neste momento. Membros da Dyad podem conversar livremente. Neste momento não há interação entre os diferentes grupos para não afetar os resultados. A Dyad deve procurar escrever no mínimo 3 ideias (mesmo número do Método 635).

Etapa 3 - Ideias N-L

Esta etapa é baseada na geração de ideias por brainstorm, utilizando o modelo New-Lamarckian (N-L). O condutor do workshop apresenta as restrições do JS usando os slides e orienta as dyads a passarem a sua folha de ideias ND para outra dyad (antihorário).

a. As ideias de um grupo são passadas para outra dyad (uma dyad não pode ficar com as mesmas ideias que escreveu). Todos as dyads recebem duas novas folhas do "Guia de Trabalho" com a numeração III, e a IV que trata da forma que as ideias devem ser escritas (contida no Apêndice 7 [POSSAMAI 2020]), que trata das restrições do jogo sério (New-Lamarckian) que precisam ser consideradas no design das mecânicas de jogo. Estas restrições são apresentadas na forma de desafios que os participantes vão procurar superar. As ideias são reescritas em forma textual nas folhas de cor verde.

b. Os membros da dyad reescrevem as ideias ou criam novas ideias para tentar superar os desafios (restrições) propostos.

Etapa 4 - Combinação de Ideias

Esta etapa está baseada em uma das técnicas do brainstorming onde novas ideias são geradas com base em ideias previamente já existentes. Os grupos são instruídos a gerar novas ideias escritas com base na combinação de ideias recebidas ou tomando como referência ideias que receberam de outros grupos. 
a. A dyads trocam as ideias modificadas na etapa 3. Cada $d y a d$ recebe metade das ideias de outra dyad.

b. Cada dyad combina as ideias recebidas entre si, criando novas ideias, ou gerando novas ideias com base nas ideias que receberam. Gerar no mínimo 3 novas ideias (por combinação ou por referência).

Etapa 5 - Visualização de Ideias

O "Guia de Trabalho" com todas as folhas entregues até esta etapa podem ser consultadas pelas dyads neste momento. As dyads são instruídas a gerar novas ideias através do desenho de ideias que eles têm na sua mesa, sejam elas suas ideias próprias ou de outros grupos.

a. As dyads trocam as ideias da etapa 4 .

b. Para cada ideia, o grupo deve procurar fazer o sketching destas ideias de forma a visualizá-las. Gerar no mínimo 3 desenhos.

Etapa 6-Checkpoint

a. Trocar os sketches entre dyads.

b. Avaliar e registrar se os sketches atendem aos objetivos e as restrições apresentados para o JS.

c. Gerar uma priorização dos sketches aderentes aos objetivos e restrições.

Etapa 7 - Revisão das ideias

Esta etapa está baseada no Brainstorming e Convergência de ideias.

a. As dyads são dissolvidas. Todas as ideias geradas são recolhidas.

b. Para cada ideia, iniciando com as de maior aderência que foram priorizadas pelas dyads na etapa anterior, seja escrita ou desenhada, uma projeção é feita em tela, utilizando uma webcam. Participantes do workshop podem dar novas ideias ou complementar as ideias mostradas. $\mathrm{O}$ condutor anota o que os participantes geram nesta etapa.

A filtragem final das ideias e o quanto elas atendem aos objetivos sérios do jogo, suas restrições e o público-alvo é feita, após o workshop, pelos usuários finais especialistas no conteúdo (UFEs).

\section{Avaliação}

Para validar a metodologia ABCDE e seus resultados, para um mesmo JS, foi conduzido o design de mecânicas de jogo utilizando a metodologia ABCDE e o mesmo design de mecânicas utilizando outra metodologia de design de jogos sérios.

Todas as propostas de mecânicas foram avaliadas utilizando-se a Matriz Criativa de Análise de Produto - CPAM [BESEMER 1998]. Para esta pesquisa, o formulário do CPAM foi utilizado através de uma implementação on-line. Os três fatores e suas respectivas facetas tiveram seus termos traduzidos para o português, mantendo a palavra original em inglês entre parêntese logo após cada um dos termos. 
Como foram obtidos 3 resultados finais da última realização do workshop usando a $\mathrm{ABCDE}$, e para evitar comportamento tendencioso das respostas, construiu-se 6 formulários atendendo a distribuição em um quadrado latino [NEGRINI 2018]. A construção deste formulário com base no CPAM foi feita em 6 variações para que cada formulário fosse uma análise comparativa entre duas versões de mecânicas: uma com (oriunda do denominado Grupo Experimental - GE) e outra sem (oriunda do denominado Grupo de Controle - GC) o auxílio da metodologia ABCDE.

Os formulários foram agrupados em 2 tipos: o que mostra o GC primeiro, seguido do GE e outro que mostra o GE primeiro seguido do GC. O GC se mantém o mesmo em todos os formulários (a imagem que é apresentada do GC), mas a imagem do GE muda, para cada uma das 3 variações obtidas no workshop.

Os formulários F1, F2 e F3 correspondem ao primeiro grupo, e os formulários F4, F5 e F6 ao segundo grupo. Estes formulários foram distribuídos entre os 2 perfis de avaliadores como mostra a Figura 3. Como há dois perfis distintos e seis variações de formulário, os formulários F2 e F5 foram distribuídos entre os dois perfis no quadro latino, metade para cada perfil de forma que o número de formulários de cada grupo (F1,F2 e F3 no primeiro grupo e F4, F5 e F6 no segundo grupo) fosse o mesmo.

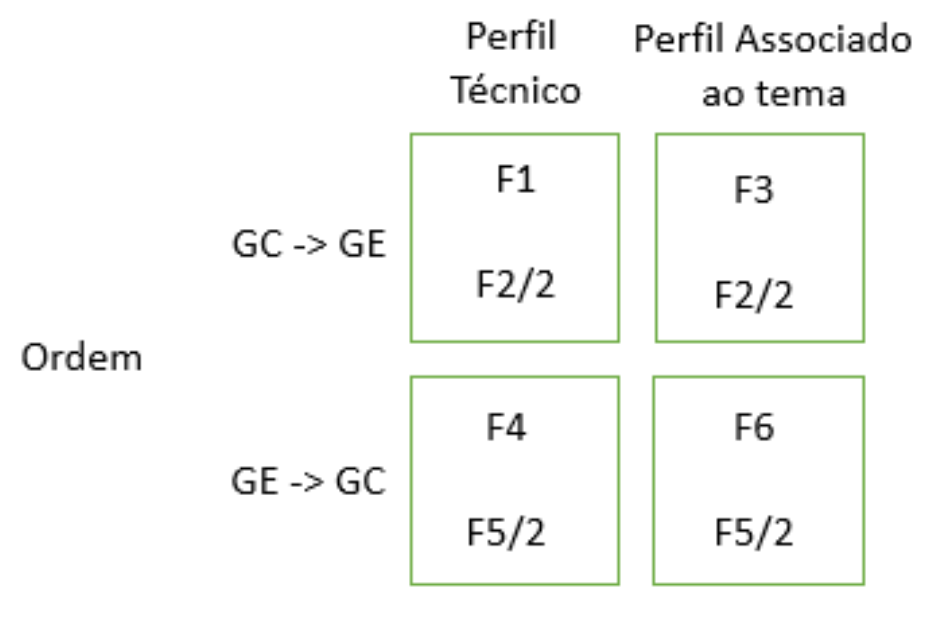

Figura 3. Distribuição dos formulários por perfil.

A proposta oriunda do GC neste contexto é caracterizada por: um candidato a mestrado, fazendo disciplinas como aluno especial e ao mesmo tempo iniciando os estudos para definição do trabalho de pesquisa. O candidato era professor de programação em curso técnico. Contou com uma fase de estudo para identificação do problema, análise da importância da área (Psicomotricidade e Lateralidade), estudo dos conceitos e definição do processo de design a ser adotado, entre 20/09/17 a 19/12/2018. O processo de design utilizado foi influenciado por um exergame sério desenvolvido anteriormente [FARIAS et al 2013], pela proposta de level design orientado a jogos sérios deste tipo [FARIAS et al 2014] e por um processo de design de jogos sérios de origem acadêmica [GRIMES, SANTOS e HOUNSELL 2018]. A concepção do jogo (geração de GDD) foi feita entre 12/3/2019 a 19/11/2019 e as reuniões eram feitas 1 vez a cada 2 meses, envolvendo somente o candidato e o futuro orientador, 1 hora por encontro. O referido projeto foi suspenso em dezembro de 2019. 
Cada um dos formulários on-line CPAM criados de para este projeto foi construído com este pareamento da proposta do GC com uma das três propostas do GE, onde os três primeiros formulários mostravam primeiro, na forma de uma imagem única a proposta $\mathrm{GC}$, seguida de uma das três propostas advindas do $\mathrm{GE}$ - respectivamente a proposta $\mathrm{A}, \mathrm{B}$ e $\mathrm{C}$ - também na forma de uma imagem única contendo os conceitos de mecânicas. Outros três formulários continham primeiro uma imagem das propostas do GE seguida de uma imagem da proposta GC. As seis versões dos formulários foram enviadas para 274 pessoas de ambos os perfis: técnico e associado ao uso/tema do jogo sério (de lateralidade), sendo 100 pessoas da área técnica e 174 pessoas associadas ao tema. Para levantamento de perfil dos respondentes, foram feitas as seguintes perguntas logo no começo destes formulários:

Q1. Você se identifica mais com qual destes dois grupos? (Técnico ou Associado ao Conteúdo); Q2. Qual sua (principal) área de atuação? ; Q3. Quanto tempo tem na sua área de atuação?; Q4. Quanto tempo por semana costuma jogar e ou assistir gameplay (video game "console", computador, celular, tablet, no navegador da internet, jogos de tabuleiro, jogos de rpg, jogos de cartas colecionáveis, twitch, youtube)?

Ao final 17(dezessete) pessoas responderam os formulários. Os resultados deste levantamento de perfil estão compilados na Tabela 2.

Tabela 2. Respostas as perguntas no formulário de avaliação por respondente

\begin{tabular}{|c|c|c|c|c|c|}
\hline Formulário & id & Q1: Pefil & Q2: Atuação & Q3: Experiência & Q4: Joga \\
\hline \multirow{3}{*}{$\mathrm{F} 1$} & Respondente 1 & Técnica & Professor / Educador & 15 & $4-7 \mathrm{~h}$ \\
\hline & Respondente 2 & Técnica & Professor / Educador & 9 & $1-2 \mathrm{~h}$ \\
\hline & Respondente 3 & Técnica & Modelagem 3D & 1 & $2-4 \mathrm{~h}$ \\
\hline \multirow{2}{*}{$\mathrm{F} 2$} & Respondente 4 & Associada & Administração & 7 & Até $1 \mathrm{~h}$ \\
\hline & Respondente 5 & Técnica & Estudante & 3 & $4-7 \mathrm{~h}$ \\
\hline \multirow{2}{*}{$\mathrm{F} 3$} & Respondente 6 & Técnica & Professor / Educador & 3 & $4-7 \mathrm{~h}$ \\
\hline & Respondente 7 & Técnica & Área da Computação & 5 & $2-4 \mathrm{~h}$ \\
\hline \multirow[b]{2}{*}{$\mathrm{F} 4$} & Respondente 8 & Associada & Comunicação Social & 17 & $2-4 h$ \\
\hline & Respondente 9 & Técnica & $\begin{array}{l}\text { Avaliação de Jogos } \\
\text { Sérios }\end{array}$ & 3 & $1-2 h$ \\
\hline \multirow{2}{*}{ F5 } & Respondente 10 & Técnica & Área da Computação & 3 & $4-7 \mathrm{~h}$ \\
\hline & Respondente 11 & Técnica & Arte e Ilustração & 2 & $7-12 \mathrm{~h}$ \\
\hline \multirow{6}{*}{ F6 } & Respondente 12 & Técnica & Game Designer & 0 & $\begin{array}{c}\text { Mais de } \\
20 \mathrm{~h}\end{array}$ \\
\hline & Respondente 13 & Técnica & Professor / Educador & 10 & $1-2 \mathrm{~h}$ \\
\hline & Respondente 14 & Associada & Psicologia & 23 & Até $1 \mathrm{~h}$ \\
\hline & Respondente 15 & Técnica & Professor / Educador & 22 & $2-4 \mathrm{~h}$ \\
\hline & Respondente 16 & Técnica & Desenvolvedor de Jogos & 2 & $1-2 \mathrm{~h}$ \\
\hline & Respondente 17 & Técnica & Arte e Ilustração & 1 & $7-12 \mathrm{~h}$ \\
\hline
\end{tabular}

Fonte: próprio autor. 
Para cada formulário, os perfis foram divididos de forma igualitária, de maneira a ter um número similar preenchendo cada uma das seis variações, resultando no grupo técnico em cerca de 16 pessoas por grupo e no de associação de 29 pessoas por grupo. As seis variações de formulários, denominadas respectivamente de F1,F2,F3,F4,F5 e F6 tiveram a seguinte distribuição de respostas após o período de dois meses, de acordo com a Tabela 3.

Tabela 3. Respostas ao formulário de avaliação e divisão entre perfis

\begin{tabular}{|c|c|c|c|}
\hline $\begin{array}{c}\text { Variantes de } \\
\text { Formulários }\end{array}$ & Técnicos & Associados & Preenchidos (total) \\
\hline F1 & 3 & 0 & 3 \\
\hline F2 & 1 & 1 & 2 \\
\hline F3 & 2 & 1 & 2 \\
\hline F4 & 2 & 0 & 2 \\
\hline F5 & 2 & 0 & 5 \\
\hline F6 & 4 & 1 & 17 \\
\hline Totais & 14 & 3 & \\
\hline
\end{tabular}

Fonte: próprio autor.

\subsection{Resultados}

Para cada um dos fatores (Novidade, Resolução, Elaboração e Síntese), somam-se os valores de suas facetas. Quanto maior o valor em um fator, mas criativo é a percepção. Para este trabalho foram analisados os conceitos de mecânicas de jogo para um jogo sério sobre lateralidade, sendo que a comparação é feita entre o criado pelo GC e uma das propostas geradas pelo GE usando a metodologia ABCDE. O resultado é a soma dos 3 fatores, gerando um total. Os resultados obtidos estão apresentados na Tabela 4.

A primeira área na Tabela 4 mostra os totais (soma dos três fatores do CPAM) por respondente, para cada um dos formulários online (F1 a F6) para os conceitos de mecânica de jogo apresentados na forma de desenho e texto gerados pelo GC e gerados pelo GE. As demais áreas mostram os subtotais para cada um dos fatores. No CPSS a comparação entre ambas as propostas é feita pela diferença entre os totais e também permite a comparação pelos subtotais de cada fator. Diferenças positivas apontam uma tendência para o que foi gerado sem a metodologia $\mathrm{ABCDE}$ e uma diferença negativa apontam para o que foi gerado com a ABCDE como percepção de maior criatividade.

Das 17 respostas, 11 favoreceram a percepção de criatividade nas mecânicas geradas com GC e seis favorecem as mecânicas geradas com o GE. Os demais campos da tabela, abaixo das 5 primeiras linhas (totais) demonstram as pontuações obtidas no CPSS através do CPAM para cada um dos fatores, tanto para GC quanto para GE e suas respectivas diferenças (GC - GE). Esta estratificação permite visualizar como as pontuações estão divididas em cada um dos fatores por respondente. 
Tabela 4. Resultados do CPSS com base nas avaliações coletadas com o CPAM

\begin{tabular}{|c|c|c|c|c|c|c|c|c|c|c|c|c|c|c|c|c|c|}
\hline \multirow{2}{*}{$\begin{array}{c}\text { Formulários: } \\
\text { Id respondentes }\end{array}$} & \multicolumn{3}{|c|}{ F1 } & \multicolumn{2}{|c|}{ F2 } & \multicolumn{3}{|c|}{ F3 } & \multicolumn{2}{|c|}{ F4 } & \multicolumn{2}{|c|}{ F5 } & \multicolumn{5}{|c|}{ F6 } \\
\hline & 1 & 2 & 3 & 4 & 5 & 6 & 7 & 8 & 9 & 10 & 11 & 12 & 13 & 14 & 15 & 16 & 17 \\
\hline CPSS - GC & 359 & 288 & 339 & 262 & 298 & 272 & 328 & 292 & 352 & 289 & 231 & 261 & 298 & 335 & 295 & 239 & 322 \\
\hline CPSS - GE & 281 & 286 & 312 & 310 & 295 & 279 & 304 & 273 & 325 & 286 & 246 & 265 & 255 & 316 & 183 & 257 & 292 \\
\hline Diferença & 78 & 2 & 27 & -48 & 3 & -7 & 24 & 19 & 27 & 3 & -15 & -4 & 43 & 19 & 112 & -18 & 30 \\
\hline Novidade / GC & 95 & 15 & 90 & 37 & 51 & 55 & 76 & 77 & 76 & 66 & 61 & 49 & 36 & 79 & 73 & 64 & 84 \\
\hline Novidade/ GE & 55 & 18 & 78 & 84 & 62 & 67 & 51 & 62 & 92 & 65 & 46 & 45 & 31 & 58 & 41 & 59 & 57 \\
\hline Diferença & 40 & -3 & 12 & -47 & -11 & -12 & 25 & 15 & -16 & 1 & 15 & 4 & 5 & 21 & 32 & 5 & 27 \\
\hline Resolução/ GC & 131 & 139 & 128 & 118 & 131 & 122 & 131 & 119 & 140 & 118 & 97 & 118 & 140 & 135 & 122 & 101 & 117 \\
\hline Resolução/ GE & 129 & 134 & 119 & 99 & 119 & 118 & 133 & 118 & 124 & 115 & 111 & 121 & 137 & 137 & 79 & 107 & 113 \\
\hline Diferença & 2 & 5 & 9 & 19 & 12 & 4 & -2 & 1 & 16 & 3 & -14 & -3 & 3 & -2 & 43 & -6 & 4 \\
\hline $\begin{array}{l}\text { Elaboração e } \\
\text { Síntese / GC }\end{array}$ & 133 & 134 & 121 & 107 & 116 & 95 & 121 & 96 & 136 & 105 & 73 & 94 & 122 & 121 & 100 & 74 & 121 \\
\hline $\begin{array}{l}\text { Elaboração e } \\
\text { Síntese / GE }\end{array}$ & 97 & 134 & 115 & 127 & 114 & 94 & 120 & 93 & 109 & 106 & 89 & 99 & 87 & 121 & 63 & 91 & 122 \\
\hline Diferenca & 36 & 0 & 6 & -20 & 2 & 1 & 1 & 3 & 27 & -1 & -16 & -5 & 35 & 0 & 37 & -17 & -1 \\
\hline
\end{tabular}

Fonte: próprio autor.

\section{Discussões}

Há de se considerar as possíveis limitações para esta pesquisa. Os dois fatores mais preponderantes foram o baixo número de respondentes do CPAM, de um grupo com 274 possíveis candidatos, apenas 17 responderam. O perfil predominantemente técnico dos respondentes também caracteriza uma limitação na análise dos resultados. O próprio tema do jogo sério, lateralidade focado nos conceitos de esquerda e direita e seus símbolos associados, pode ser um limitante, considerando seu escopo simplista de algo bem específico. Tanto o perfil predominante de um grupo quanto a quantidade de avaliadores podem ter um peso no resultado final, que não apresenta um número significativo de avaliadores de ambos os grupos que permita uma análise mais adequada com dados que reflitam um espectro estatístico suficiente para uma conclusão definitiva.

Precisa-se considerar a possível influência do formato do formulário online nos resultados obtidos, pois sua estrutura e apresentação podem não ter sido a maneira mais efetiva de se utilizar o CPAM, pois havia a necessidade de realizar rolagem na tela a partir de um determinado ponto para que fosse possível ver a imagem sendo analisa e a faceta sendo preenchida (ambos não ficavam ao mesmo tempo na tela). A construção de um artefato computacional com uma experiência de usuário mais adequada desta ferramenta pode gerar influência (mantendo as imagens sempre ao lado das facetas sendo preenchidas na tela, eliminando a necessidade de rolagem de tela para ver a imagem, voltar até a face para preenchimento) sobre os resultados obtidos.

O CPAM como ferramenta de avaliação de percepção de criatividade também pode ser visto como um limitante, pois embora esteja estabelecido na literatura e tenha tido sucesso para análise de percepção de criatividade em produtos [BESEMER 1998] e 
na indústria de desenvolvimento de artefatos computacionais [BROWN 2013], não é uma ferramenta direcionada especificamente para jogos e suas particularidades.

As propostas geradas na aplicação da metodologia ABCDE atendiam ao tema e às restrições do jogo sério de lateralidade, portanto sua aplicação dentro deste escopo é viável e gera resultados que são possíveis de serem utilizados no processo de desenvolvimento. $O$ escopo de jogo sério não é um fator determinante para a metodologia $\mathrm{ABCDE}$. Pode-se perceber que a especificidade de ser um jogo sério não foi usada para direcionar nenhum aspecto específico da ABCDE. Até a definição de JS foi tirada da versão final portanto, a metodologia ABCDE pode ser expandida para qualquer tipo de jogo.

É importante observar que a avaliação comparativa efetuada entre GC e GE envolveu 3 exemplares do GE e não o resultado final único que poderia ter sido selecionado como "o" mais criativo. Sendo assim, os dados obtidos não consideram a melhor solução que poderia advir da metodologia ABCDE pois não houve uma seleção final definitiva.

A ênfase do estudo foi em estruturar os processos que levam a fomentar a criatividade dos participantes no processo de forma a gerar produtos que tenham uma criatividade perceptível. O que foi mensurado foi a percepção de criatividade no resultado (e isto advém de um processo), sendo o processo apenas o meio. Portanto, não há uma inconsistência quando se analisa no final o produto, mas tendo a pesquisa focado no processo. Não obstante, não se conhece uma forma de avaliar o processo criativo de forma objetiva e que seja largamente difundida, como as diversas formas de avaliar os produtos.

O processo de seleção para a aplicação da ABCDE em jogos sérios e geração de conceitos de mecânicas focou em determinados elementos como fonte para o cálculo de pareamento de duplas no workshop. Estas informações junto com a Escala de Besemer tiveram por objetivo agrupar pessoas com conhecimentos e experiências diferentes, que constitui uma das bases para a promoção da criatividade [AMABILE 1996]. A primeira parte da seleção é modular e outros dados podem ser usados como base de pareamento, já que o cálculo é feito da escala Likert com distância Manhathan.

Não foram convidados para o workshop, representantes dos futuros jogadores (usuários finais aprendizes - UFA) porque, no presente caso (desenvolvimento da lateralidade) este público é infantil e seria cansativo para este responder o questionário de seleção ou ainda, manter concentração durante a execução do workshop. Entretanto, parece salutar envolver os UFA não só para aumentar a variabilidade do perfil dos participantes, mas para obter uma percepção de criatividade relacionada às experiências do próprio público-alvo, desde que este tenha maturidade, capacidade intelectual e letramento digital suficientes para ter potencial de contribuição à concepção do jogo.

Pela sua estrutura de apresentação, workshop estruturado, formulários e resultado na forma de desenhos que vêm de uma estruturação de ideias ao longo do workshop, a metodologia é flexível e pode ser integrada em diferentes métodos ou metodologias já estabelecidas na literatura de desenvolvimento. A metodologia ABCDE não altera nenhuma delas, mas se integra como mais uma fase. Embora tenha sido aplicada para mecânicas de jogo, há possibilidade de utilizá-la para outros fins, 
principalmente a definição de estética de um jogo, sonorização e level design por exemplo.

A metodologia ABCDE é fortemente influenciada pela concepção de que todas as pessoas são criativas. Isto amplia o público participante, facilitando o processo. A metodologia se embasa na ideia de que um agrupamento adequado de indivíduos, trabalhando em um processo devidamente estruturado e harmonioso, fará surgir soluções criativas. Portanto, não inicia pela avaliação da criatividade do indivíduo.

A Tabela 4 mostra que todos os 17 respondentes (id) atribuíram nota acima do meio da escala (204) para o CPSS tanto das mecânicas do GC quanto do GE indicando que ambas as propostas foram percebidas como tendo criatividade acima da média. Considerando as facetas individualmente, observa-se que as facetas Resolução bem como a de Elaboração e Síntese também receberam notas acima do meio da escala individual (68) mas, a faceta de Novidade obteve apenas 8 notas acima do meio da escala para GC e 4 acima para GE (dentre as 17 respostas). Isto indica que os respondentes consideram a Novidade como uma faceta deficitária para ambas as propostas de mecânicas (GC e GE).

Os resultados obtidos (Tabela 4) demonstram que, tirando três respostas em que existe uma diferença maior que $10 \%$ do máximo da escala que favorece os conceitos de mecânica sem usar a $\operatorname{ABCDE}(78,112$ e 43 pontos de diferença), a diferença total entre o gerado pelos modos com e sem o uso da metodologia ABCDE é baixa, sendo que das 17 respostas, 11 favorecem marginalmente o que foi gerado sem e 6 favorecem o que foi gerado com a metodologia.

Os respondentes responsáveis pelos 3 valores que estão mais díspares em relações aos demais (que apresentam pouca variação entre ambas as propostas) são respectivamente dos respondentes 1,13 e 15. Os dois primeiros, valores mais díspares, são professores com muitos anos de atuação na área relacionada a parte técnica. Esta característica de longo tempo de atuação na mesma área, como professor pode ser um indicativo para a discrepância na avaliação devido a uma tendência em optar por uma visão possivelmente mais voltada para a implementação do que está sendo proposto de mecânicas. Ainda, pela influência da profissão, talvez estes estivessem mais atentos ou preocupados em observar e relatar diferenças.

Os três valores discrepantes (aqueles que ficaram muito acima ou muito abaixo do valor médio dos demais resultados) tiveram, respectivamente, uma variação em relação ao valor obtido no CPAM pela proposta gerada pelo GE de 27,76\%, 16,86\% e $61,20 \%$. Já para os demais 14 resultados, a variação mínima foi de $0,7 \%$ e a variação máxima foi de 15,48\%, com uma variação média, para estes 14 resultados mais próximos de $6,69 \%$.

As propostas geradas pelo GE (onde todo o workshop gerou três propostas) aconteceram em um processo regrado pela metodologia $\mathrm{ABCDE}$ e que não necessitaram que os participantes tivessem um perfil definido ou um conhecimento prévio aprofundado sobre os detalhes técnicos do tema referente ao jogo sério. A aplicação da ABCDE demandou um período de 3 horas, com uma preparação por parte do condutor do workshop, e mais $5 \mathrm{~h}$, totalizando $8 \mathrm{~h}$, o que permite que um workshop seja preparado e conduzido no mesmo dia. A proposta gerada sem a metodologia ABCDE, gerou apenas uma única proposta conceitual de mecânicas de jogos e levou cerca de 2 anos 
para ser formulada. Para efeitos de comparação, este período deveria ser descontado do tempo "de estudo" dos fundamentos da lateralidade (cerca de 6 meses) cuja conclusão também foi usada na preparação para o GE e, também descontado o fato de que o estudo do GC estava sendo feito de forma voluntária (estudante estava explorando uma possibilidade de tema de mestrado). Sendo assim, pode-se considerar que o projeto de GC poderia ter sido alcançado em cerca de 9 meses.

\section{Conclusões e Trabalhos Futuros}

Jogos Sérios, além dos elementos encontrados em jogos com foco em entretenimento, possuem a característica de terem elementos sérios; que são os propósitos principais do jogo; e que necessitam estar bem desenvolvidos para que os resultados sérios sejam atingidos. Isto leva a um conjunto de restrições que limitam a forma como os designers de jogos e desenvolvedores criam os jogos sérios. Promover a criatividade neste ambiente de restrições de design é importante para contrapor a percepção de que jogos sérios não apresentam elementos criativos que fomentam um maior interesse dos jogadores em interagir com o jogo.

As pesquisas na literatura científica demonstram que a criatividade é debatida no âmbito do design de jogos, mas que este ainda é um campo aberto para aprofundamentos. Da análise dos fundamentos estabelecidos na literatura sobre os modelos de criatividade e de ferramentas que utilizam estes fundamentos no design de jogos, criou-se a metodologia $\mathrm{ABCDE}$ que foi aplicada ao design de um jogo sério sobre lateralidade.

Adotou-se um foco nas mecânicas de jogos e em jogos sérios devido a poucas pesquisas feitas que trouxessem trabalhos que abordassem estes dois pontos em específico. Como mecânicas de jogos são essenciais para a existência e caracterização de um jogo, entende-se que estas têm impacto no design de um jogo.

Desenvolver uma nova metodologia que aborde a criatividade no processo de design de mecânicas de jogos, com os elementos restritivos que fazem parte destes tipos de jogos, não é trivial e demostra a versatilidade e usabilidade das ferramentas de brainstorming, ideação e sketching quando associadas a Teoria da Criatividade Componencial e ao pensamento Divergente-Convergente.

Dos 17 resultados obtidos pela avaliação utilizando o CPAM e o CPSS. Observou-se que a percepção de criatividade nos conceitos de mecânicas de jogo apresentadas, geradas pelo GC e pelo GE, foram ambas acima da média e aproximadas. Como o GE acontece em 8h e o GC comparado levou 9 meses, a metodologia ABCDE se mostrou mais eficaz.

Em termos gerais, os dados (Tabela 4) mostram que os respondentes tiveram uma percepção de criatividade acima da média para todas as propostas, apesar que (ambas) demonstrarem uma avaliação menor na faceta Novidade. Os resultados gerados pelo GE usando a metodologia $\mathrm{ABCDE}$ conseguem chegar a uma percepção de criatividade assemelhada à do que foi gerado pelo GC num espaço de tempo consideravelmente menor e sem a necessidade de uma pesquisa extensa ou preparação/treinamento dos participantes sobre o tema do jogo sério, suas implicações e limitações, sem também envolver participantes avaliados/considerados criativos basicamente qualquer pessoa pode ser envolvida. 
Contudo devido a todas as limitações citadas para esta pesquisa e o baixo número de dados para análise, não é possível afirmar que a metodologia ABCDE gera uma percepção maior de criatividade nos conceitos de mecânicas de jogo gerados. Em contrapartida, o tempo para obtenção de resultados adequados e utilizáveis é curto e pode ser feito com qualquer grupo de pessoas. Portanto, dos aspectos associados ao projeto criativo de mecânicas de jogos sérios, os resultados sugerem que a metodologia ABCDE alcança os mesmos altos patamares de percepção de criatividade, porém, com tempo significativamente reduzido e com alta flexibilidade de recursos humanos envolvidos. Estas vantagens concorrem para tornar o projeto significativamente menos custoso

A metodologia $\mathrm{ABCDE}$ consiste em um caminho estruturado e regrado para a realização de um objetivo que é replicável e utilizável por diversas pessoas e grupos. Jogos sérios são desenvolvidos utilizando metodologias centradas nos aspectos sérios do jogo, e portanto, uma metodologia como a $\mathrm{ABCDE}$, que pode ser inserida em outras metodologias já existentes, na fase conceitual, sem alteração de desenvolvimento e com ferramentas simples constitui-se em um facilitador para a concepção criativa de futuros jogos sérios.

Conclui-se que a metodologia $\mathrm{ABCDE}$ facilita a concepção de conceitos de mecânicas de Jogos Sérios pois pode: ser integrada em outras metodologias já existentes; não exige um aprofundamento ou conhecimento extenso sobre Jogos Sérios e sobre o tema abordado; pode ser aplicada com qualquer grupo de pessoas; não exige nenhum recurso computacional; é aplicável em um tempo curto e; os resultados sobre a percepção de criatividade são equivalentes a propostas de mecânicas obtidas sem o uso da metodologia ABCDE. A metodologia ABCDE pode ser ampliada, estendida e melhorada em trabalhos úteis, mas de limitada contribuição científica:

Aplicação da metodologia conduzida por uma pessoa que não estava envolvida na pesquisa para validar a estrutura da $\mathrm{ABCDE}$, sua compreensão e uso por qualquer pessoa que não tenha tido contado com sua concepção e construção e validar os resultados obtidos na forma de propostas de mecânicas de jogos na forma de desenhos ao final do workshop - validando desta forma seu uso por qualquer pessoa;

Aplicação da metodologia para outros elementos de jogos (level design, arte). Mecânicas de jogos constituem a estrutura principal de um jogo, mas arte e level design complementam estas mecânicas, todas funcionando em conjunto. As restrições em Jogos Sérios também afetam estes outros elementos, e como estes também são alvo da fase concepção, a aplicação da ABCDE para estes elementos fornecerá novos dados;

Desdobramentos (novas pesquisas que surgiram por causa da proposta da metodologia $\mathrm{ABCDE}$ ou durante a pesquisa): Adaptação e validação do CPAM, que tem foco em produto para uma ferramenta que reflita os elementos e a criatividade no contexto específico de jogos digitais, alterando os vocábulos nos espectros, buscando gerar uma associação mais direcionada entre estas palavras e e os termos usados na área de jogos.

\section{Agradecimentos}

Os autores gostariam de agradecer ao Conselho Nacional de Desenvolvimento Científico e Tecnológico (CNPq-Brasil) pelas bolsas de produtividade DT2 e à 
Fundação de Amparo à Pesquisa e Inovação do Estado de Santa Catarina (FAPESCBrasil) pelo financiamento parcial ao laboratório LARVA, T.O. No.: 2019 TR712.

\section{Referências}

Adams. E. (2010). "Fundamentals of game design”, In: New Riders, 2th edition.

Agustin, M. e Chuang, G. e Delgado, A. (2007). Game Sketching. Proceedings of the $2 \mathrm{Nd}$ International Conference on Digital Interactive Media in Entertainment and Arts.

Alvarez, J., e Djaouti, D. (2011). An introduction to Serious Game Definitions and Concepts. In Proceedings of the Serious Games \& Simulation for Risks Management Workshop, p. 11-15.

Amabile, T. M. (1983). The social psychology of creativity: A componential conceptualization. Journal of Personality and Social Psychology, 45(2), 357-376. https://doi.org/10.1037/0022-3514.45.2.357

Amabile, T. M. (1996). Creativity in context: Update to the social psychology of creativity. Boulder, CO: Westview Press.

Amabile T. M., Barsade S. G., Mueller J. S., Staw B. M. Affect and creativity at work. Admin. Sci. Q. 2005;50:367-403.

Amabile, Teresa \& A Schatzel, Elizabeth \& Moneta, Giovanni \& J Kramer, Steven. (2004). Leader Behaviors and the Work Environment for Creativity: Perceived Leader Support. The Leadership Quarterly. 17. 5-32. 10.1016/j.leaqua.2003.12.003.

Baker, J. (2014). Video Games: Their Effect on Society and How We Must Modernize Our Pedagogy for Students of the Digital Age, Virginia Commonwealth University, Thesis, available at: https://scholarscompass.vcu.edu/etd/3627/.

Baranauskas M.C.C., Souza C.S. de, Pereira R. (2015). I GranDIHC-BR -- Grand Research Challenges for Human-Computer Interaction in Brazil. Human-Computer Interaction Special Committee (CEIHC) of the Brazilian Computer Society.

Basadur, M.S., and Finkbeiner, C.T. (1983). Measuring Preference for Ideation in Creative Problem Solving, McMaster University Research and Working Group, Working Paper Series \#208.

Besemer, S. P, O'Quin, K., (1989). The development, reliability, and validity of the revised Creative Product Semantic Scale. Creativity Research Journal, 2(4), 267-278.

Besemer, S. P. (1998). Creative Product Analysis Matrix: Testing the model structure and a comparison among products-Three novel chairs. Creativity Research Journal, $11,333-346$.

Besemer, S. P., \& O'Quin, K. (1987). Creative product analysis: Testing a model by developing a judging instrument. In S. G. Isaksen (Ed.), Frontiers of creativiw research: Beyond the ba- sics (pp. 341-357). Buffalo, NY: Bearly Ltd

Boscarioli C, Araujo R.M., Maciel S.R., (2017). I GranDSI-BR: Grandes Desafios de Pesquisa em Sistemas de Informação no Brasil (2016-2026) -Relatório Técnico. Comissão Especial de Sistemas de Informação (CE-SI) da Sociedade Brasileira de Computação (SBC). 
Buchinger, D., Hounsell, M. da S. (2013) Jogos Sérios Competitivo-Colaborativos: Um Mapeamento Sistemático da Literatura. II Congresso Brasileiro de Informática na Educação (CBIE 2013). XXIV Simpósio Brasileiro de Informática na Educação (SBIE 2013).

Black,Paul E. "Manhattan distance", in Dictionary of Algorithms and Data Structures [online], Paul E. Black, ed. 11 February 2019. Available from: https://www.nist.gov/dads/HTML/manhattanDistance.html

Brathwaith, Brenda; Schreiber, Ian.Challenges for Game Designers. Course Technology 2009.

Brophy D. R. A comparison of individual and group efforts to creatively solve contrasting types of problems. Creativity Res. J. 2006;18:293-315.

Brown, D.C. (2013). Developing computational design creativity systems. International Journal of Design Creativity and Innovation 1(1), 43-55.

Craft A. Teaching Creativity: Philosophy and Practice. New York: Routledge; 2000.

Dansey, N., \& Stevens, B. (2008). Facilitating creativity without restrictions: a pilot implementation of an idea generation game. In A. Lugmayr, F. Mayra, H. Franssila, $\&$ K. Lietsala (Eds.), Mindtrek08: proceedings of the 12th International Conference on Entertainment and Media in the Ubiquitous Era (pp. 29-33). ACM. http://dl.acm.org/citation.cfm?id=1457199\&picked=prox

Diamond A., Barnett W. S., Thomas J., Munro S. Preschool program improves cognitive control. Science. 2007;318:1387-1388.

Erb, U. \& de Araújo, Leonardo \& Königschulte, Anke \& Klein, L. \& Simonow, N.. (2012). Serious Games for Exhibition Contexts Limitations and Design Decisions. 10.4018/978-1-4666-0149-9.ch036.

Farias, E. H.; Hounsell, M. da S.; Blume, L. B. ; Ott, F. R. ; Cordovil, F. V. P . MoviLetrando: Jogo de Movimentos para Alfabetizar Crianças com Down. In: XXIV Simpósio Brasileiro de Informática na Educação, 2013. v. 1.

Farias, E. H. ; Oliveira, H. C. ; Hounsell, M. da S. ; Rossito, G. M. . MOLDE - a Methodology for Serious Games Measure-Oriented Level DEsign. In: Simpósio Brasileiro de Jogos e Entretenimento Digital, 2014, Porto Alegre (RS). SBGames 2014. Porto Alegre (RS): SBC - Sociedade Brasileira de Computação, 2014. p. 2938.

Finke R. A., Ward T. B., Smith S. M. Creative Cognition: Theory, Research and Applications. Boston, MA: MIT Press; 1996.

Fullerton, T. Game Design Workshop, Second Edition: A Playcentric Approach to Creating Innovative Games. Morgan Kaufmann, 2008.

Furnham, A. and Yazdanpanahi, T. (1995) Find in CUMINCAD Personality Differences and Group versus Individual Brainstorming , Person. Individ. Diff., 1995, 19(1), 73-80

Gabora, Liane. (2002). Cognitive Mechanisms Underlying the Creative Process. Proceedings of the Fourth Creativity and Cognition Conference 
Geschka, H., Reibnitz v., U.: "Vademecum der Ideenfindung", Battelle-Institut e.V. Frankfurt/M., 1981.

Gottel, T. e Schild, J. (2011). Creativity Room 5555. Evoking Creativity in Game Design amongst CS Students. Proceedings of the 16th Annual SIGCSE Conference on Innovation and Technology in Computer Science Education, ITiCSE 2011, Darmstadt, Germany, June 27-29, 2011.

Guilford, J.P. (1950) Creativity. American Psychologist, 5, 444-454.

Grimes, R. H. ; Santos, A. M. ; Hounsell, M. da S. . O Processo de Design de um Sistema Biomédico com Jogo Sério e Dispositivo Especial para Reabilitação Respiratória. In: Simpósio Brasileiro de Jogos e Entretenimento Digital, 2018, Foz do Iguaçu (PR). XVII SBGames. Porto Alegre (RS): SBC - Sociedade Brasileira de Computação, 2018. p. 1-10

Hadzinsky C. (2014) A Look into the Industry of Video Games Past, Present, and Yet to Come. CMC Senior Theses. Paper 842.

Hevner, A., March, S., Park, J., Ram, S.: Design Science in Information Systems Research. MIS Quarterly 28, pp. 75--105 (2004)

Hornecker, E., (2010) Creative idea exploration within the structure of a guiding framework: the card brainstorming game. In Proc. TEI 2010, ACM Press, 101-108.

Johnson-Laird, P. N. (1988). Freedom and constraint in creativity. In R. J. Sternberg (Ed.), The nature of creativity: Contemporary psychological perspectives (p. 202219). Cambridge University Press.

Kaufman J. C., Beghetto R. A. (2008) Exploring mini-C: creativity across cultures. In: DeHaan R. L., Narayan K.M.V., editors. Education for Innovation: Implications for India, China and America. Rotterdam, The Netherlands: Sense Publishers;pp. 165180 .

Kaufman J. C., Sternberg R. J. Creativity. Change. 2007;39:55-58.

Koestler A. The Act of Creation. Arkana, 1964. 751 pages.

Michael, David \& L. Chen, Sandra. (2006). Serious Games: Games That Educate, Train, and Inform.

Haring-Smith T. (2006) Creativity research review: some lessons for higher education. Association of American Colleges and Universities. Peer Rev.8:23-27.

Hunicke, R., Chapman, V., AI for Dynamic Difficulty Adjustment in Games. In Proceedings of the Challenges in Game AI Workshop, Nineteenth National Conference on Artificial Intelligence (AAAI '04) (San Jose, California) AAAI Press, 2004.

Hunicke, Robin \& Leblanc, Marc \& Zubek, Robert. (2004). MDA: A Formal Approach to Game Design and Game Research. AAAI Workshop - Technical Report. 1.

Osborn, A. F.How to think up. New York, McGraw-Hill, 1942.

Parnes, S.J. (1967) Creative Behavior Guidebook. Scribners, New York. 
Possamai, D S; Enfatizando a criatividade no game design de jogos sérios. 2020. $195 \mathrm{f}$. Dissertação (Mestrado)-Universidade do Estado de Santa Catarina, Programa de PósGraduação em Computação Aplicada, Joinville.

Possamai, D.S, Hounsell, M. da S., Gasparini, I (2018). A Criatividade no Design de Jogos Digitais: Um Mapeamento Sistemático da Literatura. TISE 2018, XXIII Conferência Internacional sobre Informática na Educação.

Ralph, Paul \& Monu, Kafui. (2015). Toward a Unified Theory of Digital Games. The Computer Games Journal.

Rohrbach, Bernd: "Kreativ nach Regeln - Methode 635, eine neue Technik zum Lösen von Problemen". Creative by rules - Method 635, a new technique for solving problems first published in the German sales magazine "Absatzwirtschaft", Volume 12, 1969. p73-75 and Volume 19, 1 October 1969.

Rhodes, M. (1961). An analysis of creativity. The Phi Delta Kappan, 42(7), 305-310.

Sawyer R. K. Explaining Creativity: The Science of Human Innovation. New York: Oxford University Press; 2006.

Schell, Jesse. A book of Lenses. CRC Press: 2008.

Simon, H. A. The Sciences of the Artificial. 3rd ed. Cambridge: MIT Press, 1996.

Simonton D. K. (2004) Creativity in Science: Chance, Logic, Genius, and Zeitgeist. Oxford, United Kingdom: Cambridge University Press.

Sowrey, T. 1989. Idea generation: identifying the most useful techniques, European Journal of Marketing 24(5): 20-29. doi:10.1108/03090569010140228

Sternberg, R. J. (2001). Why schools should teach for wisdom: The balance theory of wisdom in educational settings. Educational Psychologist, 36(4), 227-245.

Sternberg, R. J., \& Lubart, T. I. (1995). Defying the crowd: Cultivating creativity in a culture of conformity. New York: Simon \& Schuster Inc.

Sternberg, R. J., \& Williams, W. M. (1996). How to develop student creativity. Alexandria, VA: Association for Supervision and Curriculum Development.

Sternberg, R. J. (1985). Implicit theories of intelligence, creativity, and wisdom. Journal of Personality and Social Psychology, 49(3), 607-627.

Thornburg, T.H. (1991), Group Size \& Member Diversity Influence on Creative Performance. The Journal of Creative Behavior, 25: 324-333. https://doi.org/10.1002/j.2162-6057.1991.tb01145.x

Vandervert L. R., Schimpf P. H., Liu H. How working memory and the cerebellum collaborate to produce creativity and innovation. Creativity Res. J. 2007;9:1-18.

Walk, Wolfgang \& Görlich, Daniel \& Barrett, Mark. (2017). Design, Dynamics, Experience (DDE): An Advancement of the MDA Framework for Game Design.

Winter, J. e Jantke, K. P. (2014). Formal Concepts and Methods Fostering Creative Thinking in Digital Game Design. IEEE 3rd Global Conference on Consumer Electronics (GCCE). 
Zyda, M.; 2005. From Visual Simulation to Virtual Reality to Games. In: IEEE Computer Society. Disponível em< http://gamepipe.usc.edu/ zyda/pubs/ZydaIEEEComputer-Sept2005.pdf> 